\title{
Parasitic pneumonia in roe deer (Capreolus capreolus) in Cornwall, Great Britain, caused by Varestrongylus capreoli (Protostrongylidae)
}

\author{
Victor R. Simpson ${ }^{1 *}$ and Damer P. Blake ${ }^{2}$ (D)
}

\begin{abstract}
Background: Roe deer (Capreolus capreolus) became extinct over large areas of Britain during the post mediaeval period but following re-introductions from Europe during the 1800s and early 1900s the population started to recover and in recent decades there has been a spectacular increase. Many roe deer are shot in Britain each year but despite this there is little published information on the diseases and causes of mortality of roe deer in Great Britain.

Case presentation: The lungs of two hunter-shot roe deer in Cornwall showed multiple, raised, nodular lesions associated with numerous protostrongylid-type nematode eggs and first stage larvae. There was a pronounced inflammatory cell response (mostly macrophages, eosinophils and multinucleate giant cells) and smooth muscle hypertrophy of the smaller bronchioles. The morphology of the larvae was consistent with that of a Varestrongylus species and sequencing of an internal transcribed spacer-2 fragment confirmed 100\% identity with a published Norwegian Varestrongylus cf. capreoli sequence. To the best of the authors' knowledge this is the first confirmed record of $V$. capreoli in Great Britain. Co-infection with an adult protostrongylid, identified by DNA sequencing as Varestrongylus sagittatus, was also demonstrated in one case.

Conclusions: Parasitic pneumonia is regarded as a common cause of mortality in roe deer and is typically attributed to infection with Dictyocaulus sp. This study has shown that Varestrongylus capreoli also has the capability to cause significant lung pathology in roe deer and heavy infection could be of clinical significance.
\end{abstract}

Keywords: Roe deer, Capreolus, Varestrongylus, Pneumonia, Protostrongylid

\section{Background}

Roe deer (Capreolus capreolus) and European red deer (Cervus elaphus elaphus) are the only species of deer native to the British Isles. Although historically widespread, roe deer became extinct over large areas of Britain during the post mediaeval period, particularly in Wales and the English Midlands [1, 2]. However, following re-introductions from France, Germany, Austria and Siberia during the 1800 s and early 1900 s $[1,3]$ roe deer populations in Britain started to recover and it is now believed that all roe deer in southern England are

\footnotetext{
* Correspondence: vic@wildlifevic.org

${ }^{1}$ Wildlife Veterinary Investigation Centre, Chacewater, Truro, Cornwall TR4 8PB, UK

Full list of author information is available at the end of the article
}

derived from animals introduced from Europe [2]. In recent decades there has been a spectacular increase in the British roe deer population [4] and, with the rate of range expansion recently estimated at $2.3 \%$, per annum, this is expected to expand further for the foreseeable future [5]. The factors that are driving this and other deer population trends in Britain are poorly understood and there is a need for an evidence-based understanding of the mechanisms involved [6]. Increased roe deer density has previously been implicated in the enhanced spread of pathogens such as Mycobacterium bovis [7] and might increase the risk of chronic wasting disease (CWD) transmission should it reach the UK [8]. When combined with climate changes which may support larger mollusc populations [9], and a concomitant enhanced 
risk of transmission of mollusc-vectored pathogens, there is a greater risk that parasites such as Varestrongylus capreoli will become established in the UK. Many roe deer are shot in Britain each year for human consumption and also to limit the damage they do to commercial woodland [10]. Despite this, there is little published information on the diseases and causes of mortality of roe deer in this country.

\section{Case presentation}

\section{Samples and sample preparation}

The lungs and, in one case the majority of the lung lobes, from two adult male roe deer were submitted to the Wildlife Veterinary Investigation Centre by hunters in April 2015 and April 2017 following the observation of gross abnormalities for the purpose of food safety. Both deer were shot by licenced marksmen as part of estate management strategies at locations denoted by National Grid Reference numbers SX08 64 and SW84 45, respectively. One animal (case \#1) had been shot because it was lame, having suffered a recent amputation of the left forelimb distal to the carpus; despite this injury it was in quite good physical condition. The second animal (case \#2) was shot for human consumption and was judged to be in good body condition. The lungs in each case were subjected to gross examination and showed multiple swellings in the parenchyma. In order to check for the possible presence of parasite eggs or larvae impression smears from the cut surface of the swellings were made on to microscope slides; a small amount of normal saline was added, a coverslip applied and the specimen examined by direct light microscopy. Duplicate impression smears were mounted in dilute Lactophenol Cotton Blue to clear and stain the characteristic features of any parasitic forms present. In case \#1 only an additional smear was air-dried, heat-fixed and stained by Ziehl-Neelson in order to check for the presence of acid-fast organisms such as Mycobacterium sp.. Larvae and parasite appendages were measured using an eye-piece micrometer calibrated against a stage micrometer. Representative sections through several parenchymal swellings of both sets of lungs were placed in $10 \%$ neutral buffered formalin, dehydrated through graded alcohols, embedded in paraffin wax, sectioned at $5 \mu \mathrm{m}$ and stained by haematoxylin and eosin (H\&E) and periodic acid-Schiff (PAS). Additionally, lungs from case \#2 were examined by fine blunt dissection for the presence of adult nematodes. Fragments of dissected lung were pooled, placed in a glass beaker with $2 \mathrm{~L}$ of tap water, thoroughly agitated, left to settle and then the sediment examined for parasites or fragments.

\section{Gross pathology}

The lungs in case \#1 showed multiple tan-coloured, nodular, roughly $2-5 \mathrm{~cm}$ diameter swellings located mostly along the margins of the lobes. They were clearly demarcated from the lung parenchyma, had a firm, uniform consistency and frequent small ecchymotic haemorrhages. Also present in the parenchyma were localised areas of atelectasis and haemorrhage (Fig. 1). There was a small number of adult Dictyocaulus sp. nematodes present in the bronchi and larger bronchioles. The nodular lung lesions in case \#2 were very similar to those in the first case but were often surrounded by a zone of parenchyma that was much paler than elsewhere in the lung.

\section{Bacteriology}

No acid-fast organisms were seen in a Ziehl-Neelsen stained, air-dried and heat-fixed impression smear from the cut surface of a lung nodule in case \#1.

\section{Histopathology}

The nodular lesions in both cases showed dense consolidation with very large numbers of nematode eggs present in various stages of development together with numerous larvae in the bronchioles and the alveolar lumena. Associated with this was a large number of inflammatory cells, mostly macrophages, eosinophils and multinucleate giant cells, and fibrosis of alveolar walls (Fig. 2). The smaller bronchioles showed pronounced smooth muscle hypertrophy and were surrounded by a thick layer of lymphocytes (Fig. 3). No adult nematodes were seen in the nodules or in unaffected lung parenchyma.

\section{Parasitology}

There were moderate numbers of adult Dictyocaulus sp. in the bronchi and bronchioles of case \#1 but none were seen in case \#2.

In both cases microscopic examination of wet impression smears from the cut surface of the nodules revealed numerous first stage nematode larvae and embryonated eggs. The larvae had a dorsal spike at the base of the tail

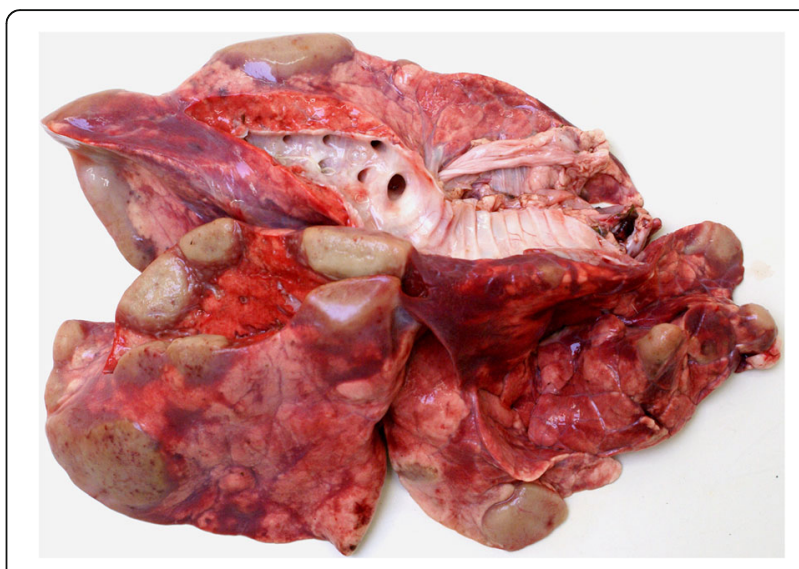

Fig. 1 The gross appearance of the lungs in case \#1 showing multiple pale tan nodular swellings in the pulmonary parenchyma 


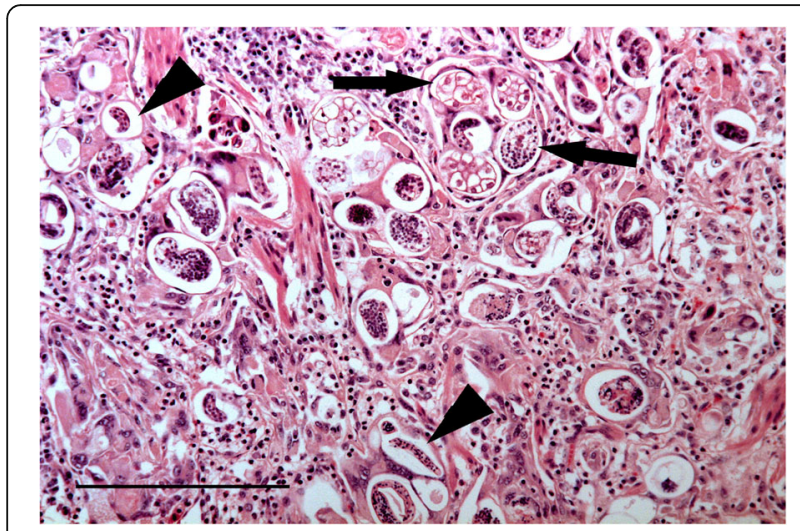

Fig. 2 Histological section through a nodular swelling in the lungs of case \#1. Note the eggs in various stages of development (arrows) and first stage larvae (arrow heads) H\&E stain. Bar $=200 \mu \mathrm{m}$

appendage and the appendage itself had well-developed cuticular folds (Fig. 4). The larvae in case \#2 were measured and the mean dimensions $(n=10)$ were length 294.4 $\mu \mathrm{m}$ (standard error 3.3) and width $18.8 \mu \mathrm{m}(0.7)$.

Blunt dissection of lung parenchyma was carried out in case \#2 only. Examination of the sediment after washing the pooled fragments of lung tissue revealed a single male nematode measuring approximately $5 \mathrm{~mm}$ in length. It had well developed bursae with radiating rays that did not extend fully to the margins. The spicules were tubular, equal, symmetrical and yellowish brown and measured $258.5 \mu \mathrm{m}$ (Fig. 5).

\section{Molecular biology}

Total genomic DNA was extracted from (i) pooled L1 larvae recovered from an additional unfixed impression smear sample from case \#2 only and (ii) a single adult male preserved in $70 \%(v / v)$ ethanol, using a Qiagen DNeasy Blood and Tissue kit following the animal tissues spin column protocol as described by the manufacturer

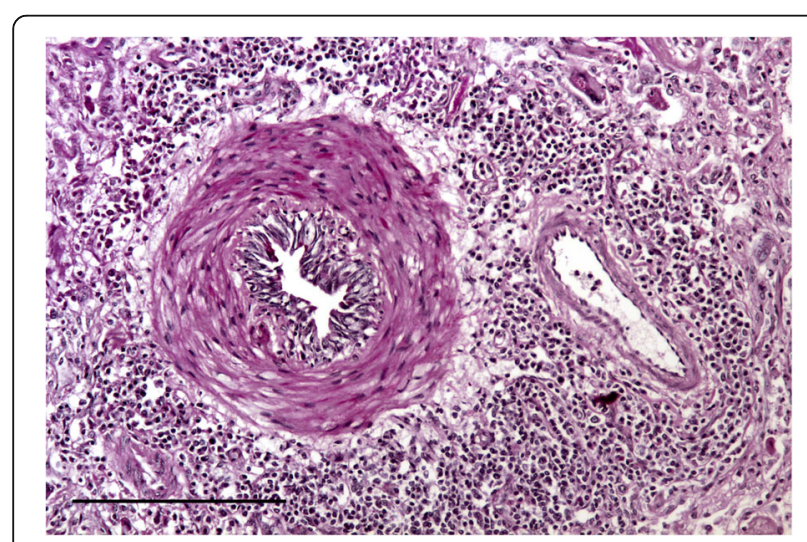

Fig. 3 Histological section through the lung of case \#1 showing severe smooth muscle hypertrophy of a small bronchiole and a surrounding rim of lymphocytes. PAS stain. Bar $=200 \mu \mathrm{m}$

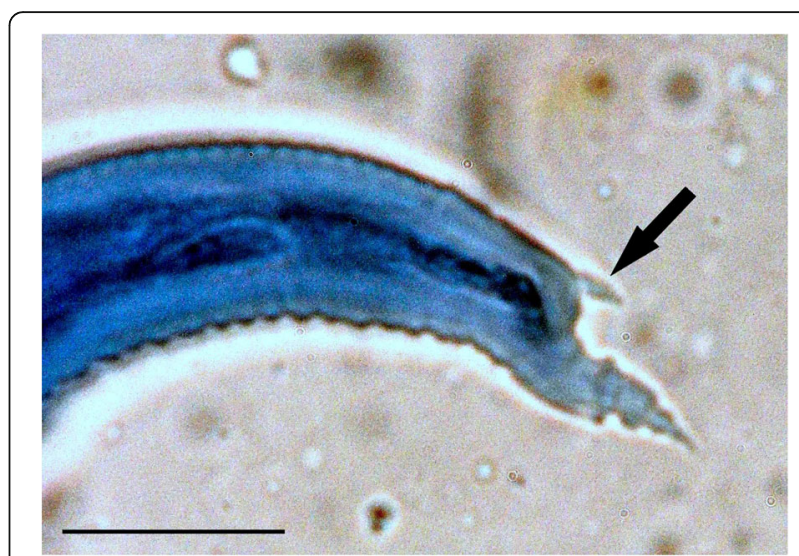

Fig. 4 High power view of the tail appendage with cuticular ridges and the dorsal spine (arrow) of a first stage larva in an impression smear from a lung nodule in case \#2. Lactophenol Cotton Blue stain. Bar $=25 \mu \mathrm{m}$

(Qiagen, Hilden, Germany). A fragment of the internal transcribed spacer (ITS)-2 sequence within the nuclear ribosomal DNA was amplified in duplicate and sequenced from each sample using the generic pan-nematode primers NC1 (5'-ACGTCTGGTTCAGGGTTGTT-3') and NC2 (5'-TTAGTTTCTTTTCCTCCGCT-3') [11] to confirm parasite identity. Briefly, each PCR reaction contained $3 \mu \mathrm{l}$ template DNA, $1.5 \mu \mathrm{l}$ of each of the relevant forward and reverse primers $(10 \mu \mathrm{M}$ stock; Sigma-Aldrich, Poole, UK) and $20.0 \mu \mathrm{l}$ of MyTaq $\times 2$ mastermix (Bioline, London, UK), made up to a final volume of $40 \mu \mathrm{l}$ with molecular grade water (Sigma). Molecular grade water was used as a no template negative control. Thermal cycler parameters were: $1 \mathrm{x}$ initial denaturation at $95{ }^{\circ} \mathrm{C}$ for $2 \mathrm{~min}$, followed by $35 \mathrm{x}$ (denaturation $30 \mathrm{~s}$ at $95^{\circ} \mathrm{C}$, annealing $30 \mathrm{~s}$ at $52{ }^{\circ} \mathrm{C}$, extension $30 \mathrm{~s}$ at $72{ }^{\circ} \mathrm{C}$ ), followed by a final extension phase of $72{ }^{\circ} \mathrm{C}$ for $7 \mathrm{~min}$. PCR amplicons were resolved by agarose gel electrophoresis using a $1 \%(w / v)$

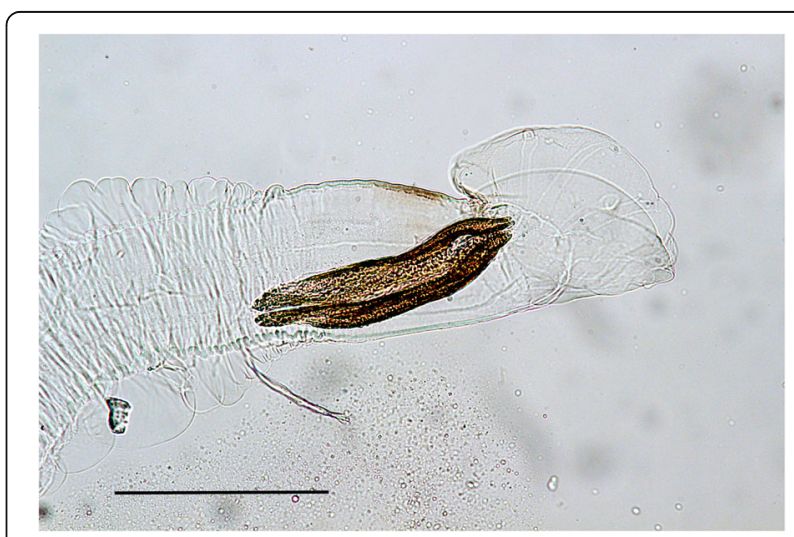

Fig. 5 Caudal end of the male protostrongylid recovered following blunt dissection of lung in case \#2. The spicules are tubular, equal size and symmetrical and the bursal rays do not extend fully to the margins. Unstained. Bar $=200 \mu \mathrm{m}$ 
UltraPure agarose gel in $1 \times$ Tris-borate-EDTA buffer (TBE; all Sigma), including 0.01\% ( $v / v)$ SafeView nucleic acid stain (NBS Biologicals). The results of electrophoresis were visualised using a U:Genius Gel Documentation System(Syngene). PCR amplicons were purified using a PCR purification kit (Qiagen) and sequenced on both strands using the same primers employed in their original amplification (GATC Biotech, Konstanz, Germany). Sequence assembly, annotation, and interrogation were undertaken with CLC Main Workbench v6.0.2 (CLC Bio, Aarhus, Denmark) using BLASTn against the GenBank non-redundant database to assign identity.

Following these methods partial ITS-2 sequences were derived from L1 larvae and the single adult male worm. In total 449 bp high quality sequence was produced in duplicate from the L1 larvae, with 100\% sequence similarity between duplicates (available under accession number LT962658). Comparison with the GenBank non-redundant nucleotide database identified the highest sequence similarity with $V$. cf. capreoli (accession number KJ452176.1; 100\% coverage, 100\% identity). Separately, $480 \mathrm{bp}$ sequence was produced in duplicate from the adult male worm (LT962657), with greatest similarity to Varestrongylus sagittatus (KJ439592.1; 100\% coverage, $100 \%$ identity). Comparison with published V. sagittatus ITS-2 sequences KJ439592-4 and KJ439596-7, revealed 15 copies of the degenerate TCG/CCG triplet repeat, which may provide future value as a genetic marker.

\section{Discussion}

The protostrongylid nematode Varestrongylus capreoli is a recognised cause of lung lesions in roe deer in Europe [12-15]. However, prior to the present study it does not appear to have been recorded in roe deer in the British Isles. A histopathological study of roe deer lungs in Scotland described infection with an unidentified protostrongylid nematode but as examination was confined to histopathology no description of the parasite other than the appearance of the eggs and larvae was provided [16]. The paper does not include a description of the gross pathology of the lungs so it is not apparent whether or not there were nodular lesions similar to those seen in the present study. However, the histopathological findings closely resembled those seen in the present Cornish cases with larvae and eggs filling alveolar lumena accompanied by eosinophils, giant cells, alveolar macrophages and some neutrophils, supporting association of the inflammatory response observed with the parasite infection. As in the present study, severe muscular hypertrophy of the smaller bronchiolar walls was a prominent feature [16].

A notable feature in both studies is the absence of adult nematodes in the histological sections. However, adults have been recorded in both alveoli and bronchioles of roe deer elsewhere in Europe [14]. A possible explanation for their absence in some instances is that they may survive for only a short while after egg laying and are phagocytosed. A similar situation exists with Capillaria hepatica infection where eggs often remain in the hepatic parenchyma after the adults have died and been resorbed (Simpson, unpublished data). However, adults of $V$. sagittatus remain viable for several years [17] and it seems unlikely that $V$. capreoli would be markedly different from this closely related species. Both deer in the present study were killed in April and showed evidence of active infection with eggs and larvae in varying stages of development. The seasonality of infection for $V$ capreoli does not appear to have been documented but $V$. sagittatus infection of maral deer (Cervus elaphus maral) peaks during winter and spring [17]; this could possibly be in relation to a period when either the molluscs which act as intermediate hosts become most active or when ingestion of infective larvae is most common. It has been postulated that parasites could infect deer during feeding on dry grass and short shrubs covered by snow in which hibernating snails occur [12, 14]. Also, the presence of immature forms in the lungs could represent a latent phase of infection $[12,14]$.

The gross appearance of the nodular lung lesions in the present study bore a superficial resemblance to lung lesions due to tuberculosis in roe deer in Spain and Italy [7]. The lesions in those cases included foci in the pulmonary parenchyma that were occasionally calcified and surrounded by a thin layer of epithelioid and multinucleated giant cells. Although no such lesions were seen in the roe deer infected with Varestrongylus $s p$. it does illustrate the need to examine lung lesions in roe deer for evidence of infection by mycobacteria.

Many conservationists may welcome the re-establishment of a former native species after it had become extinct or extremely rare. However, the recent recolonization of England by roe deer has been dramatic and shows no sign of reducing. This raises concern about an increased risk of disease transmission, such as tuberculosis, due to animals living at a higher population density [7]. In addition there is growing concern that climate change is likely to influence the geographic distribution of diseases such as bluetongue and Lyme disease [6]. There is a need to be aware of these factors from both a conservation viewpoint and also from a zoonotic perspective.

Identification of protostrongylid larvae by morphological features is not generally possible. The first stage larvae of species of the subfamilies Muelleriinae, Elaphostrongylinae and Varestrongylinae all have a dorsal spine and they also have a similar tail appendix [18]. However, the larvae of the various species have a recognised size range and this can assist in identification. In the present study the mean length of the larvae was $294.4 \mu \mathrm{m}$ and this was within the recorded range of 285-341 $\mu \mathrm{m}$ for Varestrongylus capreoli 
[17], although larvae for other Varestrongylus spp. fall within the same or similar ranges [15]. Identification was confirmed by sequencing of the ITS-2, which gave a $100 \%$ match to a published Norwegian Varestrongylus cf. capreoli sequence.

The adult male protostrongylid recovered after blunt dissection of the lung was identified by DNA sequencing as Varestrongylus sagittatus. This is known to be a common lungworm of European red, maral and fallow (Dama dama) deer in Europe and Asia where it produces small nodules in the lungs, similar to those caused by Muellerius capillaris in sheep and goats [19]. Varestrongylus sagittatus, described using the synonym Bicaulus sagittatus, has also been recorded in Britain where it was found in a roe deer buck shot in the New Forest [20]. No morphological or other data was provided to confirm the identification. Varestrongylus sagittatus is one of a group of seven Varestrongylus species which are characterised by having spicules greater than $200 \mu \mathrm{m}$. However, although they measured $258.5 \mu \mathrm{m}$ in the roe deer specimen in this study, this is significantly shorter than the range normally quoted for $V$. sagittatus (325-433.8 $\mu \mathrm{m})$ [15]. The total length of the nematode at around $5 \mathrm{~mm}$ is also much less than the accepted range for an adult male V. sagittatus (14.5$33.8 \mathrm{~mm}$, as well as for a number of other species such as $V$. alpenae $(13-15 \mathrm{~mm}), V$ alces $(11.36-14.7 \mathrm{~mm})$ and $V$ capricola $(15-18 \mathrm{~mm})$ [15]. A possible explanation for the small size of $V$. sagittatus in this study is that this is typically a parasite of red or fallow deer, not roe deer, and its development may have been restricted in an atypical host.

\section{Conclusions}

Verminous pneumonia due to infection with Dictyocaulus sp. is considered to be an important cause of mortality in roe deer in Britain $[2,21]$ and in some areas has been considered to act as the main factor controlling populations [21]. This study has shown that Varestrongylus capreoli also has the capability to cause significant lung pathology in roe deer. There is clearly a need to consider the possible involvement of this parasite when investigating lung disease in roe deer, especially as mixed infections with the more obvious Dictyocaulus parasite may occur resulting in under diagnosis of $V$. capreoli.

\section{Acknowledgements}

The authors wish to thank Adrian Cross and Jeremy Preston for submitting the specimens and Abbey Veterinary Services for histopathological processing and advice. They also express their thanks to Professor Mark Fox from the Royal Veterinary College and Dr. Mark Dagleish from Moredun Research Institute for helpful discussion.

\section{Funding}

The study was funded by the Wildlife Veterinary Investigation Centre and the Royal Veterinary College. No external sources of funding were available. This manuscript has been assigned the reference PPS_01724 by the Royal Veterinary College. The funding bodies played no role in the design of the study, the collection, analysis and interpretation of data, or in writing the manuscript.
Availability of data and materials

The sequences generated in this work are publically available from the European Nucleotide Archive under the accession numbers LT962657-8.

\section{Authors' contributions}

VS performed the gross and histopathological examinations, coordinated the study and drafted the preliminary manuscript. DB carried out the molecular genetic studies. Both authors contributed to writing the draft manuscript and read and approved the final manuscript.

\section{Ethics approval}

The animals in this study were legally culled by licenced hunters following the Code of Practice, recommendations and ethics of the British Association for Shooting and Conservation for the purpose of population control. Samples were submitted and processed for the purpose of food safety and this report prepared after receiving approval from the Ethical Review Committee of the Royal Veterinary College under the reference SR2018-1617.

Consent for publication

Not applicable.

\section{Competing interests}

The authors declare that they have no competing interests.

\section{Publisher's Note}

Springer Nature remains neutral with regard to jurisdictional claims in published maps and institutional affiliations.

\section{Author details}

${ }^{1}$ Wildlife Veterinary Investigation Centre, Chacewater, Truro, Cornwall TR4 8PB, UK. ${ }^{2}$ Pathobiology and Population Sciences, Royal Veterinary College, Hawkshead Lane, North Mymms, Hertfordshire AL9 7TA, UK.

Received: 16 January 2018 Accepted: 14 June 2018

Published online: 22 June 2018

\section{References}

1. Prior R. The roe deer: conservation of a native species. London: Oxford University Press; 1995.

2. Hewison AJM and Staines BW. European roe deer (Capreolus capreolus). In: Harris S, Yalden DW, editors. Mammals of the British isles: handbook, 4th edition. The Mammal Society, Southampton. 2008. p 605-617.

3. Prior R. The roe deer of Cranborne chase. An ecological survey. London: Oxford University Press; 1968

4. Aebischer NJ, Davey PD \& Kingdon NG. National Gamebag Census: Mammal Trends to 2009. Game \& Wildlife Conservation Trust, Fordingbridge. 2011. (http://www.gwct.org.uk/ngcmammals). Accessed 22 Dec 2017.

5. Ward Al. Expanding ranges of wild and feral deer in great Britain. Mammal Rev. 2005;35:165-73

6. Newman C \& Macdonald D W. Biodiversity Climate change impacts report card Technical paper 2015 https://nerc.ukri.org/research/partnerships/ride/ Iwec/report-cards/biodiversity-source02/. Accessed 15 Apr 2018.

7. Balseiro A, Oleaga A, Orusa R, Robetto S, Zoppi S, Dondo A, Goria M, Gortázar C, Marín JF, Domenis L. Tuberculosis in roe deer from Spain and Italy. Vet Rec. 2009:164:468-70.

8. Storm DJ, Samuel MD, Rolley RE, Shelton P, Keuler NS, Richards BJ, Van Deelen TR. Deer density and disease prevalence influence transmission of chronic wasting disease in white-tailed deer. Ecosphere. 2013;4:10.

9. Sternberg M. Terrestrial gastropods and experimental climate change: a field study in a calcareous grassland. Ecol Res. 2000;15:73-81.

10. Fuller RJ, Gill RMA. Ecological impacts of increasing numbers of deer in British woodland. In: Fuller RJ, RMA G, editors. Special Issue, Forestry, vol. 74; 2001. p. 193-9.

11. Gasser RB, Chilton NB, Hoste $H$, Beveridge I. Rapid sequencing of rDNA from single worms and eggs of parasitic helminths. Nucleic Acids Res. 1993;21: 2525-6.

12. Aguirre AA, Bröjer C, Mörner T. Descriptive epidemiology of roe deer mortality in Sweden. J Wildlife Dis. 1999;35:753-62.

13. Dacal V, Vázquez L, Javier Pato F, Cienfuegos S, Panadero R, López C, DiezBaños P, Morrondo P. Cambios de la capacidad pulmonar en corzos (Capreolus capreolus) del noroeste de España infectados por nematodos broncopulmonares. Galemys. 2010;22(nºspecial):233-42. 
14. Švarc R, Pajerský A. Pathomorphological changes of roe deer lungs in the ontogeny of Varestrongylus capreoli (Stroh et Schmid 1938) Docherty, 1945. Folia Parasitol. 1990;32:315-21.

15. Verocai GC, Kutz SJ, Simard M, Hoberg EP. Varestrongylus eleguneniensis sp. n. (Nematoda: Protostrongylidae): a widespread, multi-host lungworm of wild north American ungulates, with an emended diagnosis for the genus and explorations of biogeography. Parasit Vectors. 2014; https://doi.org/10. 1186/s13071-014-0556-9.

16. Munro R, Hunter AR. Histopathological findings in the lungs of Scottish red and roe deer. Vet Rec. 1983;112:194-7.

17. Anderson RC. Nematode Parasites of Vertebrates, Their Development and Transmission. 2nd ed. Wallingford: CABI Publishing; 2000.

18. Kafle P, Lejeune M, Verocai GG, Hoberg EP, Kutz SJ. Morphological and morphometric differentiation of dorsal-spined first stage larvae of lungworms (Nematoda: Protostrongylidae) infecting muskoxen (Ovibos moschatus) in the Central Canadian Arctic. IJP-PAW. 2015;4:283-90.

19. Mason P. Elaphostrongylus cervi and its close relatives; a review of protostrongylids (Nematoda, Metastrongyloidea) with spiny-tailed larvae. Surveillance. 1995;22:19-24.

20. McDiarmid A. Appendix I. Some Parasites and Diseases of Roe Deer with Particular Reference to the Cranborne Chase Population. In: Prior R, editor. The Roe deer of Cranborne Chase. An Ecological Survey. London: Oxford University Press; 1968. p. 183-209.

21. McDiarmid A. Some disorders of wild deer in the United Kingdom. Vet Rec. 1975;97:6-9

\section{Ready to submit your research? Choose BMC and benefit from:}

- fast, convenient online submission

- thorough peer review by experienced researchers in your field

- rapid publication on acceptance

- support for research data, including large and complex data types

- gold Open Access which fosters wider collaboration and increased citations

- maximum visibility for your research: over $100 \mathrm{M}$ website views per year

At BMC, research is always in progress.

Learn more biomedcentral.com/submissions 